\title{
A Luminescent Iridium Phenanthroline Crown Ether Complex for the Detection of Silver(I) Ions in Aqueous \\ Media
}

\author{
Michael Schmittel* and Hengwei Lin
}

Center of Micro- and Nanochemistry and Engineering, Organische Chemie I, Universität Siegen, Adolf-Reichwein Str. D-57068 Siegen, Germany.

\section{Supporting information}

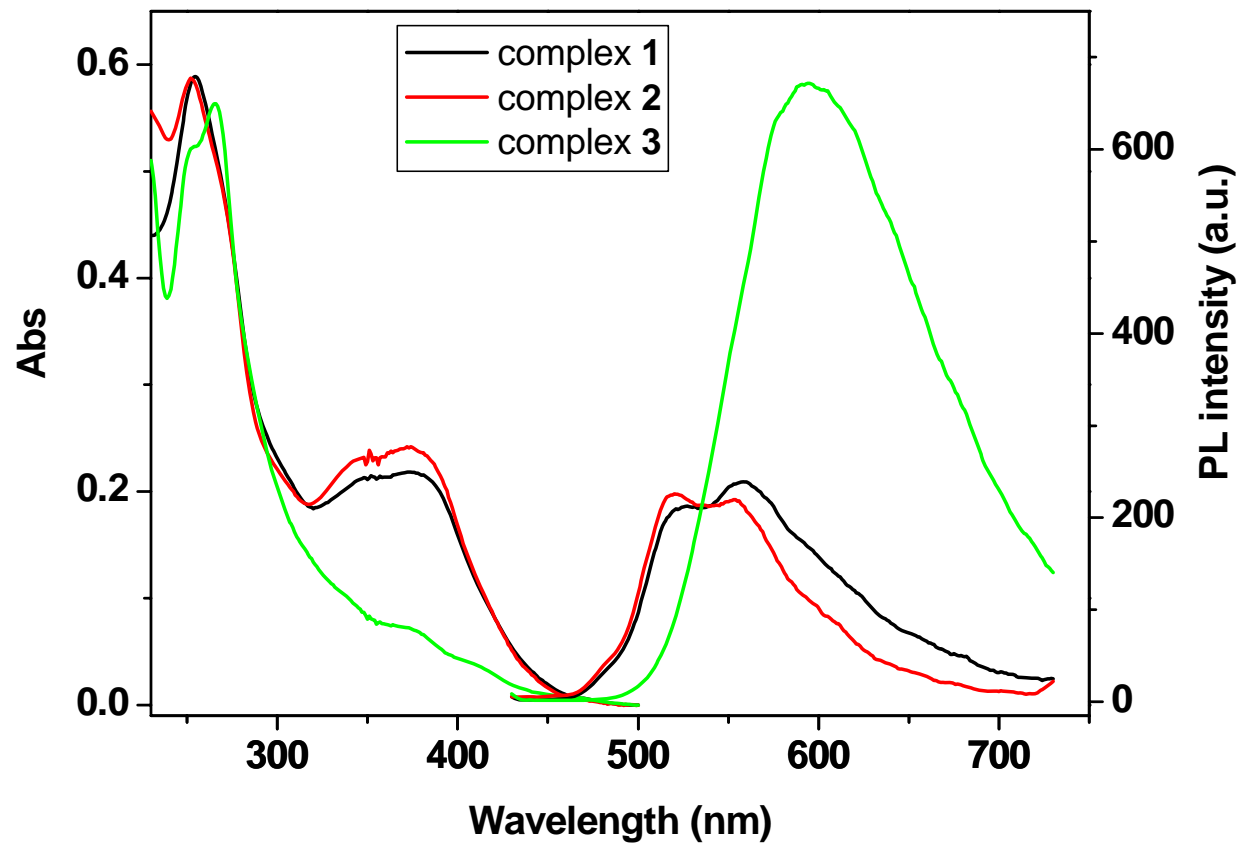

Figure S1. UV-vis absorption and luminescence spectra of 1-3 $(10 \mu \mathrm{M})$ in $\mathrm{MeCN}$. The emission spectra were obtained after excitation at $375 \mathrm{~nm}$ for $\mathbf{1}$ and 2 and $372 \mathrm{~nm}$ for $\mathbf{3}$, respectively. 


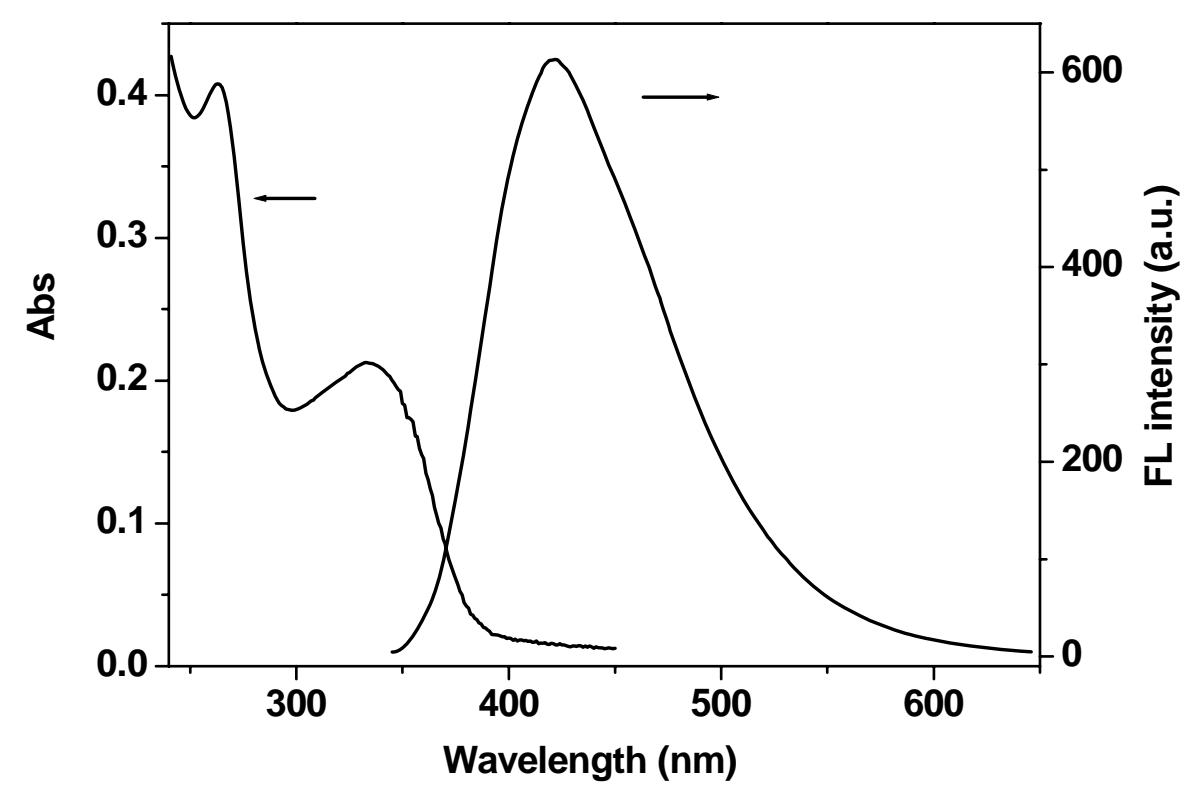

Figure S2. UV-vis and emission spectra of ligand 7 in $\mathrm{MeCN}$. The wavelength of the excitation was $335 \mathrm{~nm}$.

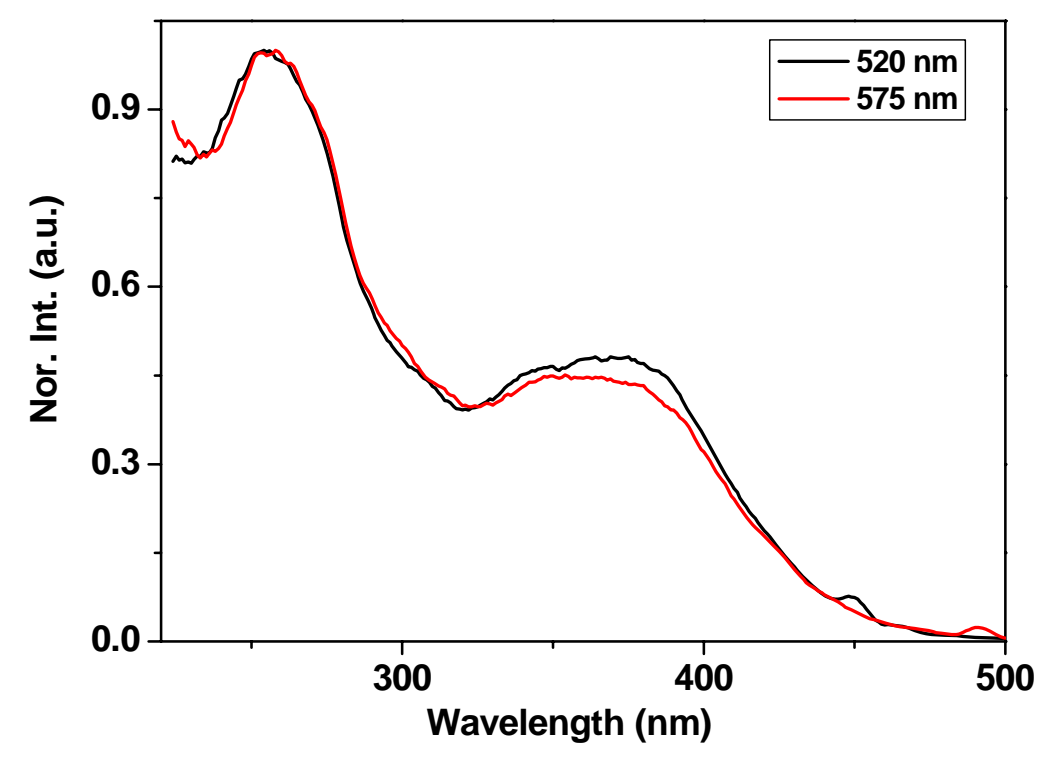

Figure S3. Normalized excitation spectra of $\mathbf{1}$ at $520 \mathrm{~nm}$ and $575 \mathrm{~nm}$. 

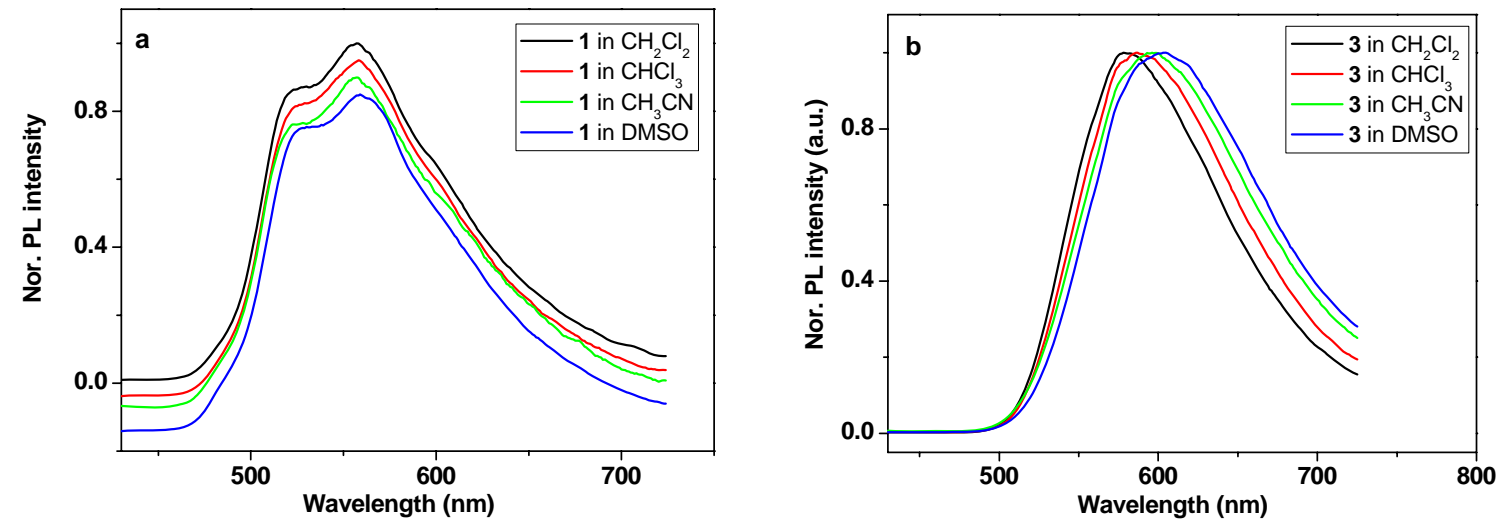

Figure S4. Normalized emission intensity of 1 (a) and 3 (b) in different solvents. The normalized emission bands of $\mathbf{1}$ in different solvents (left) were separated for clarity by 0.05 (from top to bottom).

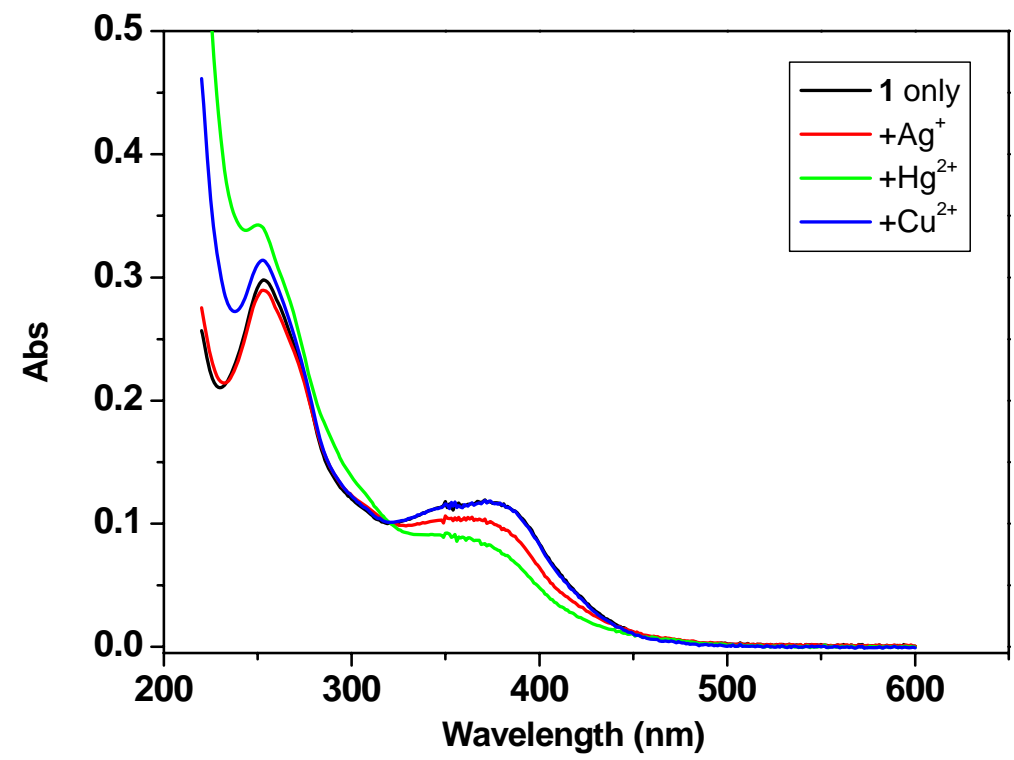

Figure S5. UV-vis response of $1\left(5.0 \mu \mathrm{M}\right.$ in $\left.\mathrm{MeCN} / \mathrm{H}_{2} \mathrm{O}=1: 1\right)$ in presence of different metal ions (100 eqs. each). Other metal ions, such as $\mathrm{Na}^{+}, \mathrm{K}^{+}, \mathrm{Mg}^{2+}, \mathrm{Ca}^{2+}, \mathrm{Ba}^{2+}, \mathrm{Ni}^{2+}, \mathrm{Co}^{2+}, \mathrm{Zn}^{2+}$, $\mathrm{Cd}^{2+}$ and $\mathrm{Pb}^{2+}$ only induced very minor responses. The spectra were omitted for clarity. 

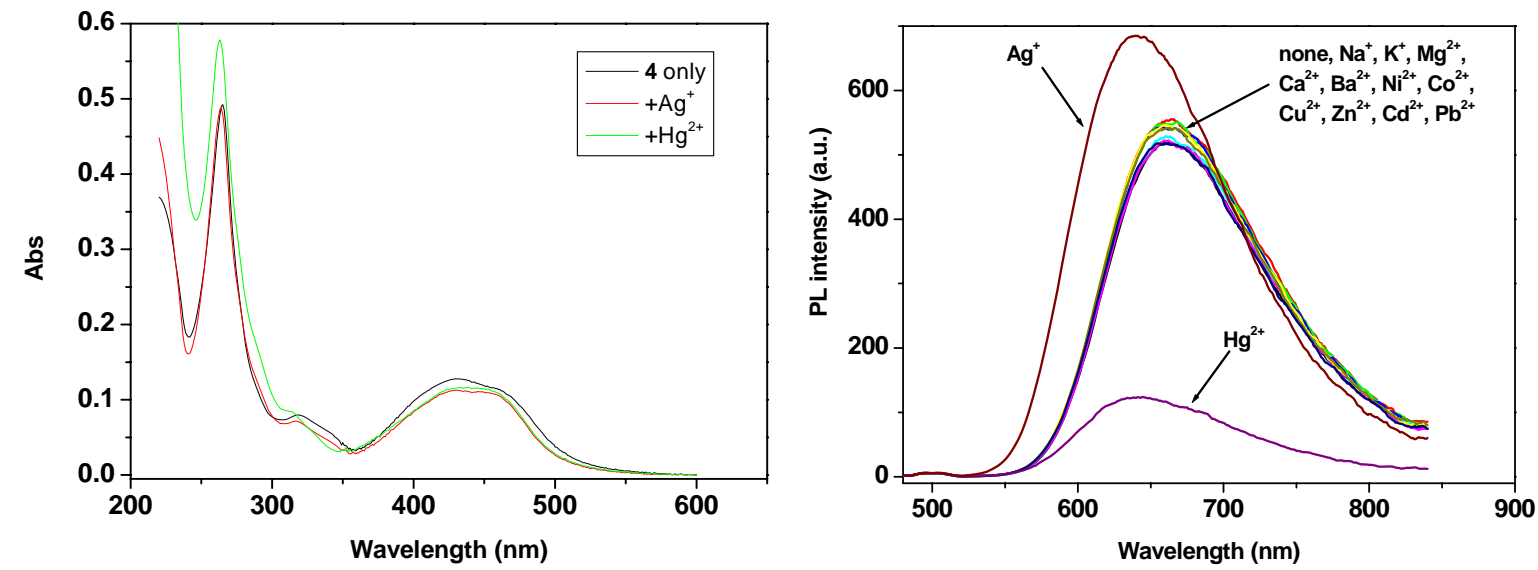

Figure S6. Left: UV-vis absorption spectra of complex $4\left(5.0 \mu \mathrm{M}\right.$ in $\left.\mathrm{MeCN} / \mathrm{H}_{2} \mathrm{O}=1: 1\right)$ upon addition of 100 eqs. of metal ions. Metal ions, such as $\mathrm{Na}^{+}, \mathrm{K}^{+}, \mathrm{Mg}^{2+}, \mathrm{Ca}^{2+}, \mathrm{Ba}^{2+}, \mathrm{Ni}^{2+}, \mathrm{Co}^{2+}$, $\mathrm{Cu}^{2+}, \mathrm{Zn}^{2+}, \mathrm{Cd}^{2+}$ and $\mathrm{Pb}^{2+}$, only induced very minor responses. The spectra were omitted for clarity.

Right: Emission spectra of $4\left(5.0 \mu \mathrm{M}\right.$ in $\left.\mathrm{MeCN} / \mathrm{H}_{2} \mathrm{O}=1: 1\right)$ upon addition of various metal ions (100 eqs. each). $\lambda_{\text {exc }}=430 \mathrm{~nm}$.
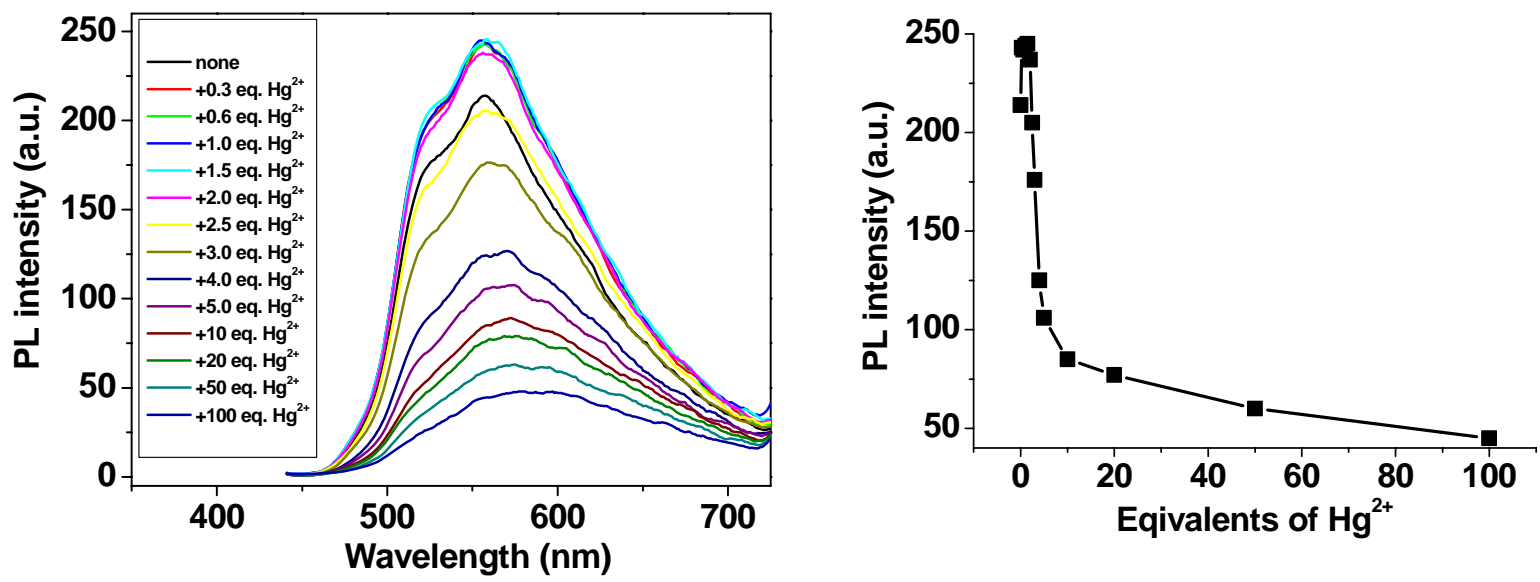

Figure S7. Left: The luminescence response of $1\left(5.0 \mu \mathrm{M}\right.$ in $\left.\mathrm{MeCN} / \mathrm{H}_{2} \mathrm{O}=1: 1\right)$ upon addition of $\mathrm{Hg}^{2+}$. Right: Relationship between luminescence intensity of $\mathbf{1}$ and amount of $\mathrm{Hg}^{2+}$ ions added. 

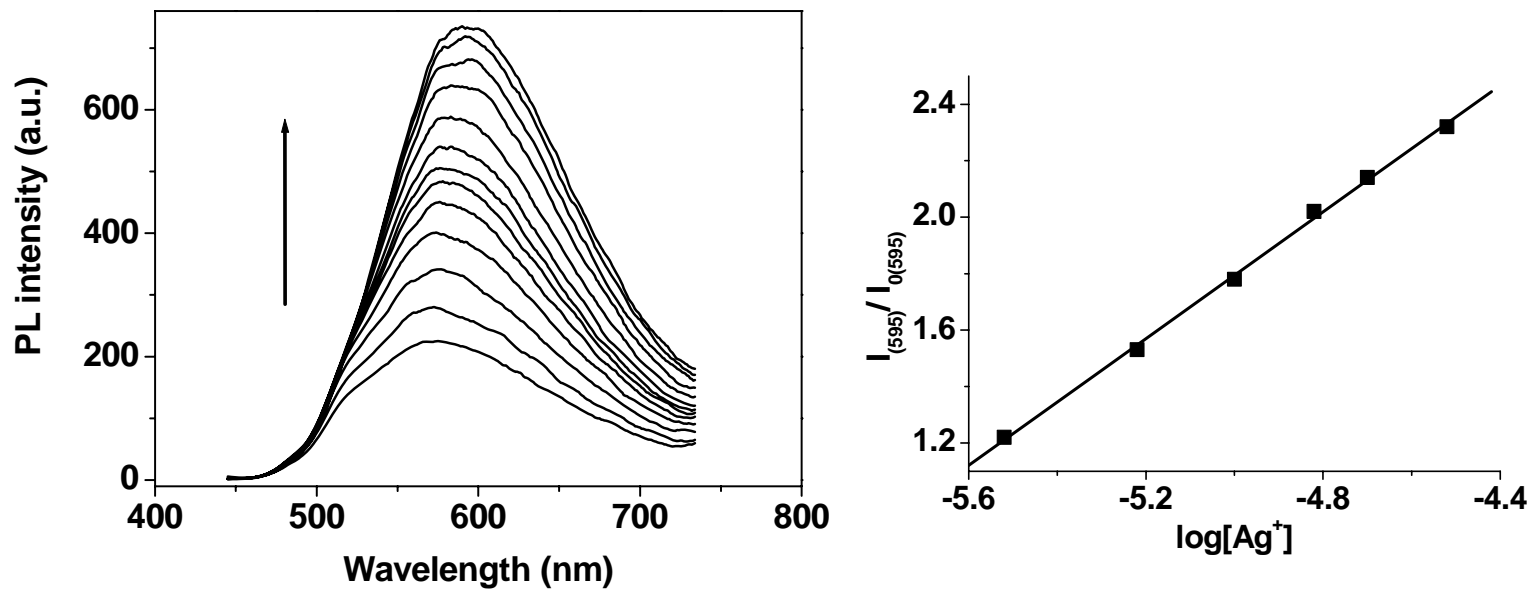

Figure S8. Left: The luminescence responses of 1 with $\mathrm{Ag}^{+}$added $(3.0,6.0,10,20,30,50$, $70,100,150,200,300$, and $500 \mu \mathrm{M})$ in the presence of physiologically important metal ions $\left(\left[\mathrm{Na}^{+}\right]=145 \mathrm{mM},\left[\mathrm{K}^{+}\right]=5 \mathrm{mM},\left[\mathrm{Mg}^{2+}\right]=2 \mathrm{mM}\right.$, and $\left.\left[\mathrm{Ca}^{2+}\right]=5 \mathrm{mM}\right)$. Right: the relationship between luminescence intensity and $\log \left[\mathrm{Ag}^{+}\right]$. 

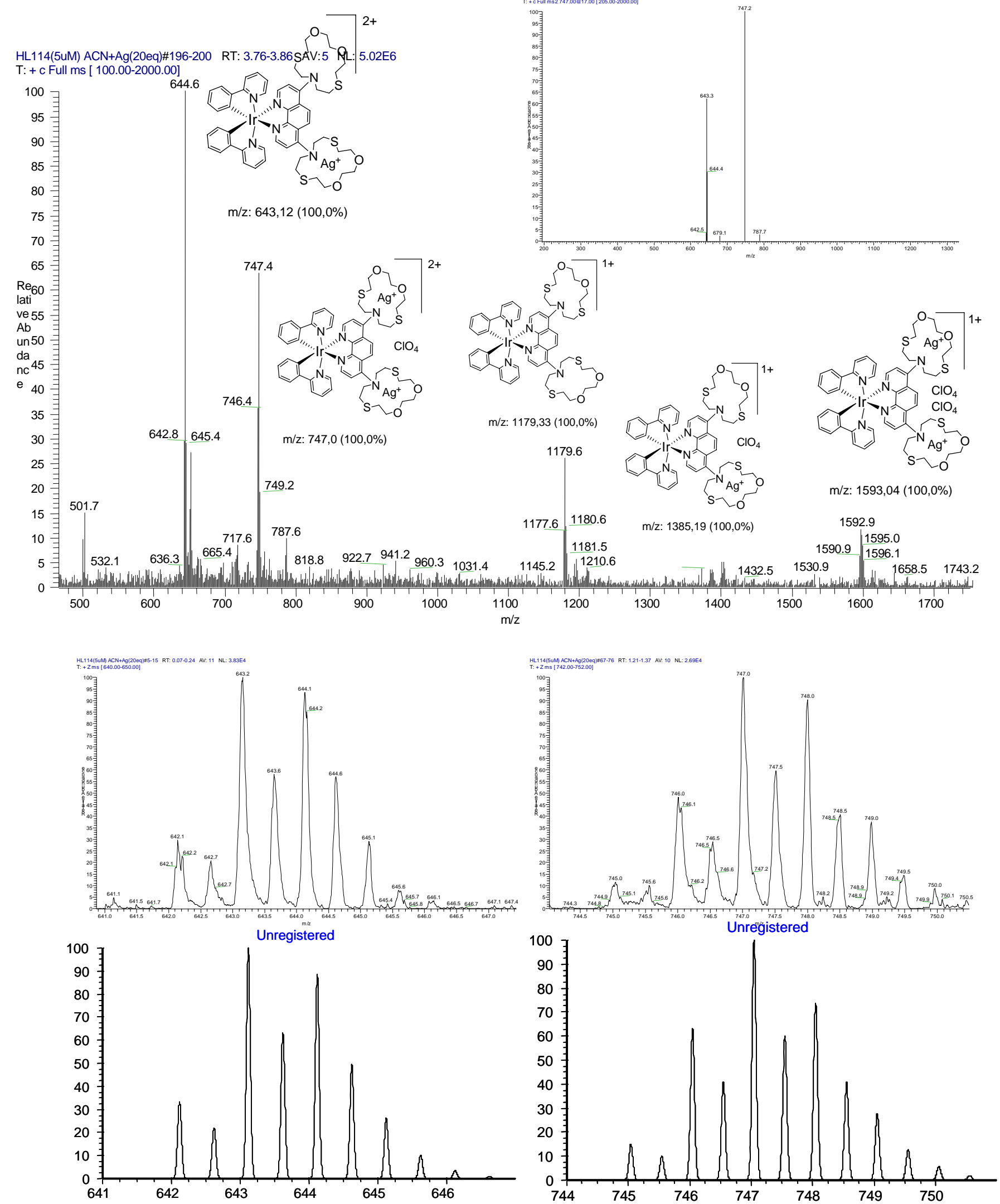

Figure S9. Full range ESI-MS of 1 in the presence of excess amount of $\mathrm{Ag}^{+}$ions (top). Experimental (middle) vs. computed (bottom) isotopic splitting of $\mathbf{1} \cdot\left(\mathrm{Ag}^{+}\right)$(left) and $\mathbf{1} \cdot\left(\mathrm{Ag}^{+}\right)_{2}$ (right). 


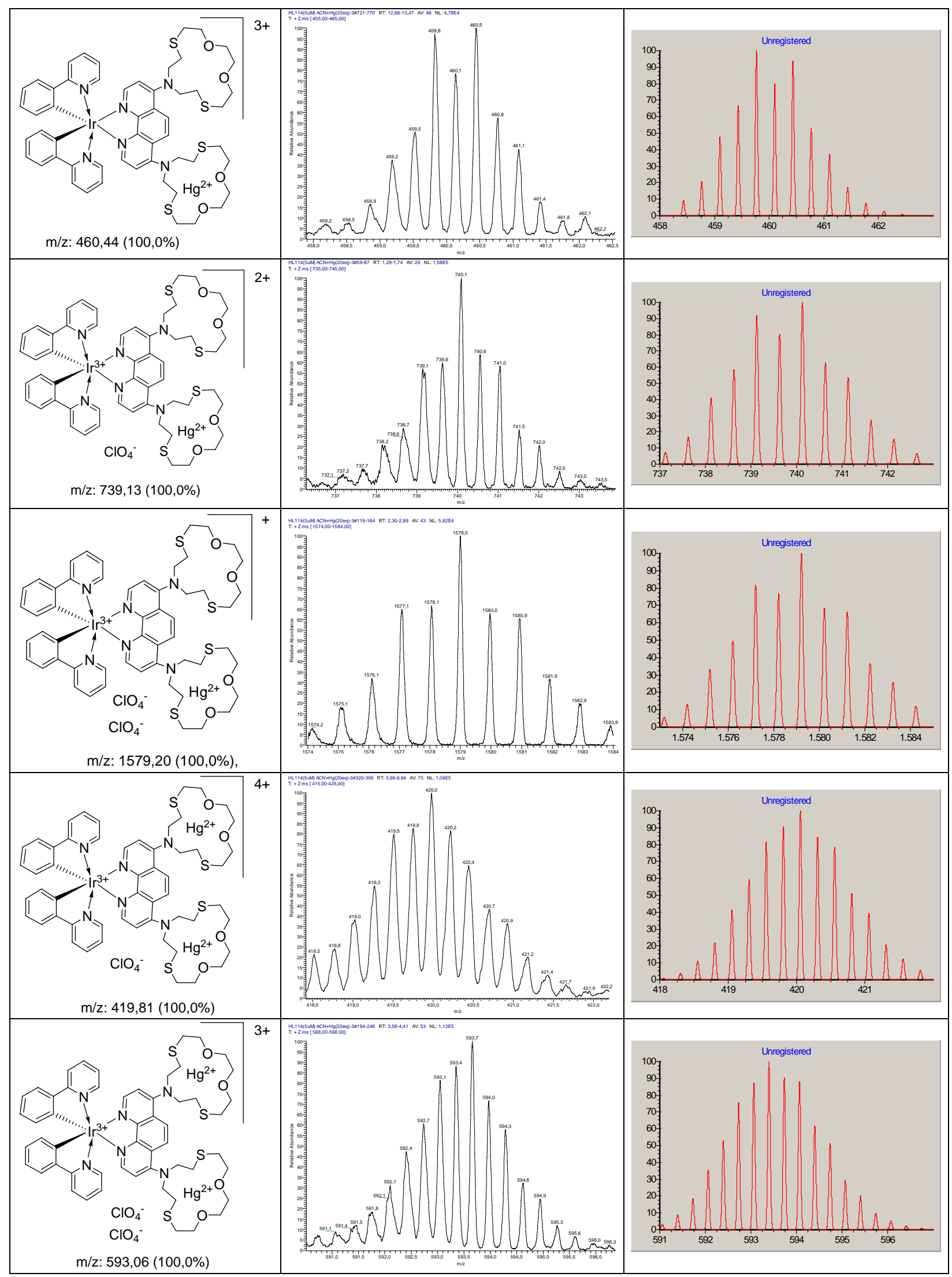




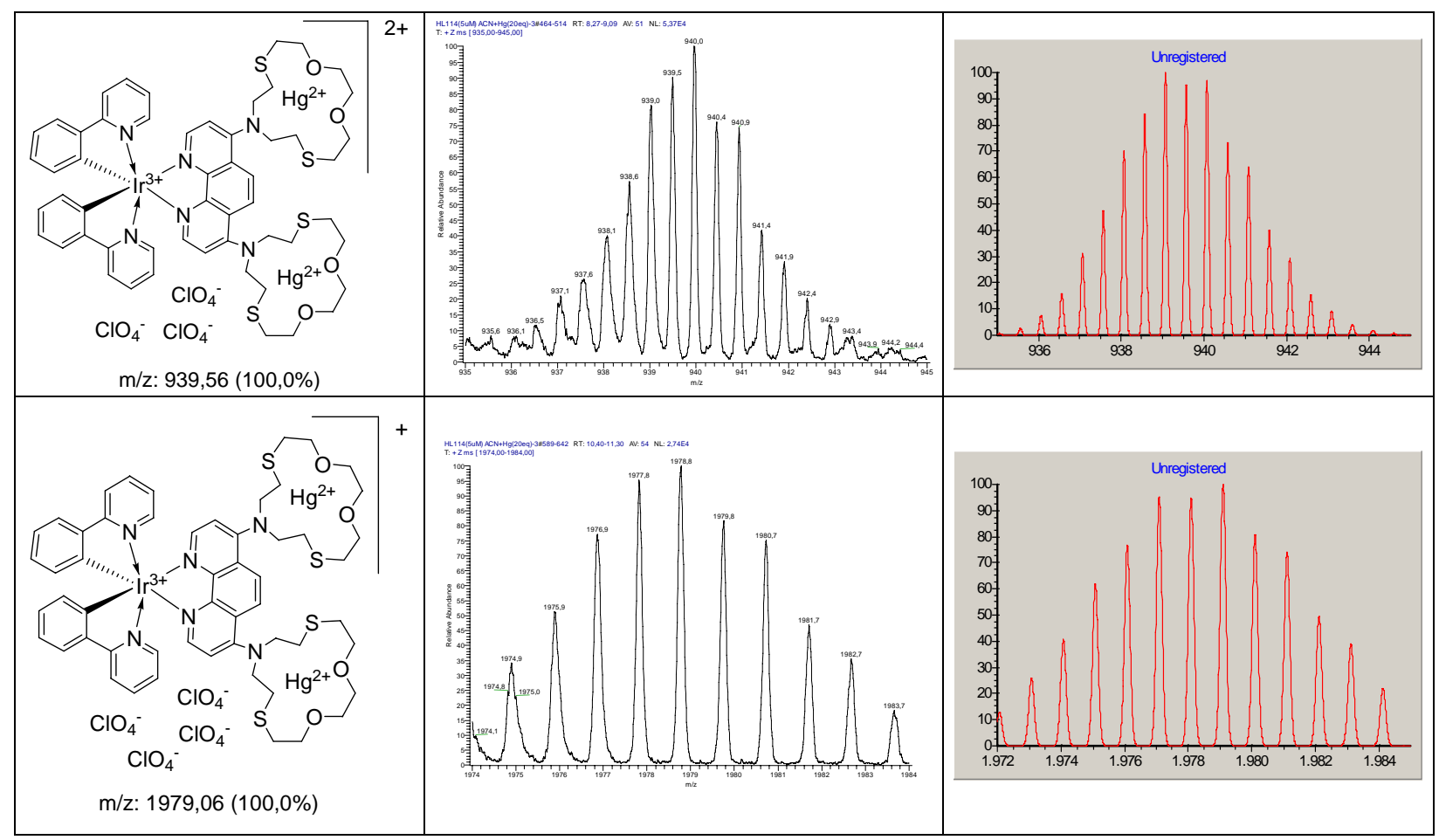

Figure S10. Several selected signals from the ESI-MS of 1 in the presence of excess amount of $\mathrm{Hg}^{2+}$. Experimental isotopic splittings are displayed in the middle column, calculated ones in the right column. 

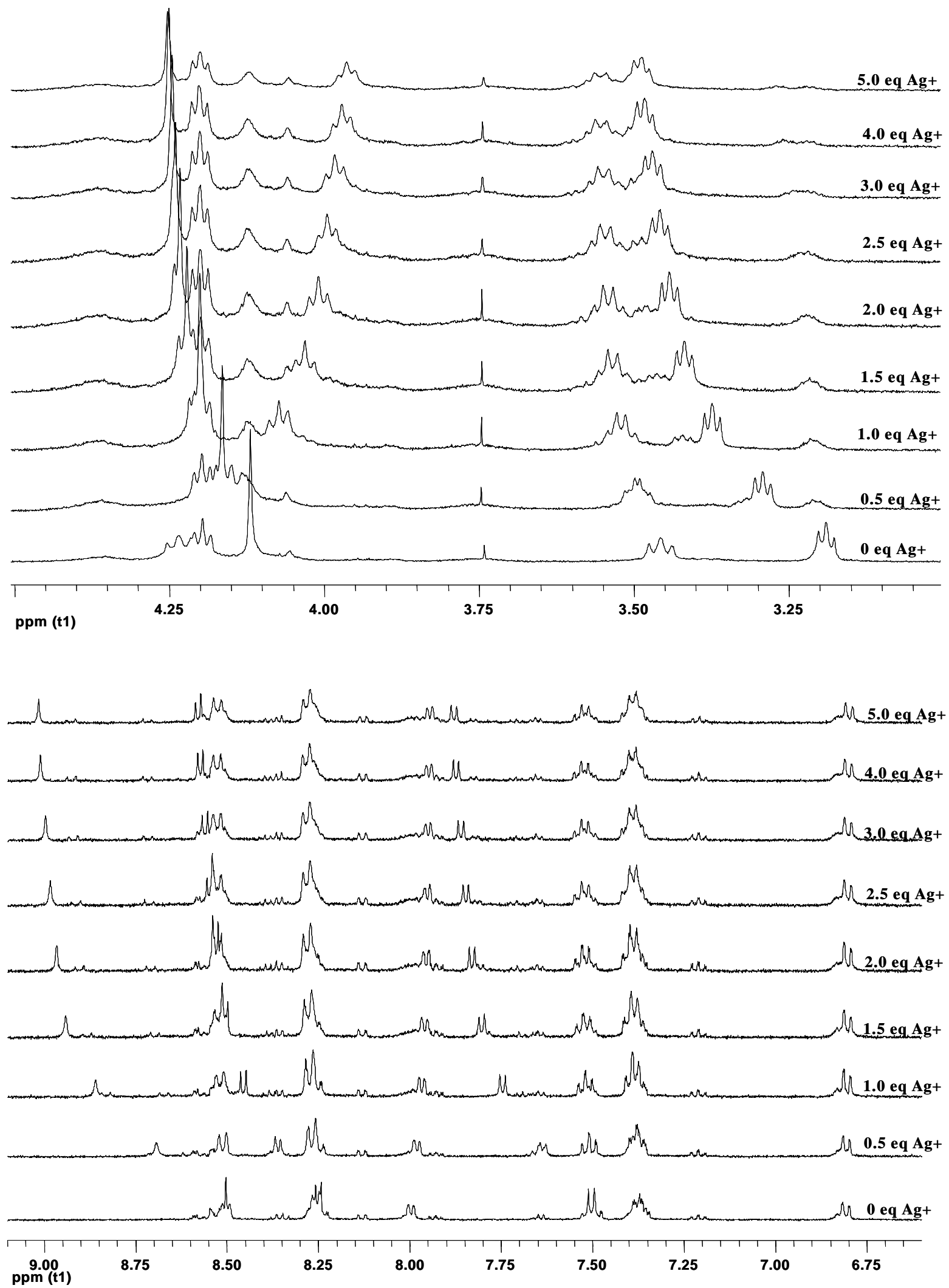

Figure S11. ${ }^{1} \mathrm{H}-\mathrm{NMR}$ of complex 1 in the presence of different amounts of $\mathrm{Ag}^{+}$. Top, azadithio-dioxa crown ether moieties of $\mathbf{1}$; bottom, 1,10-phenanthroline and 2-phenylpyridine moieties of $\mathbf{1}$. 


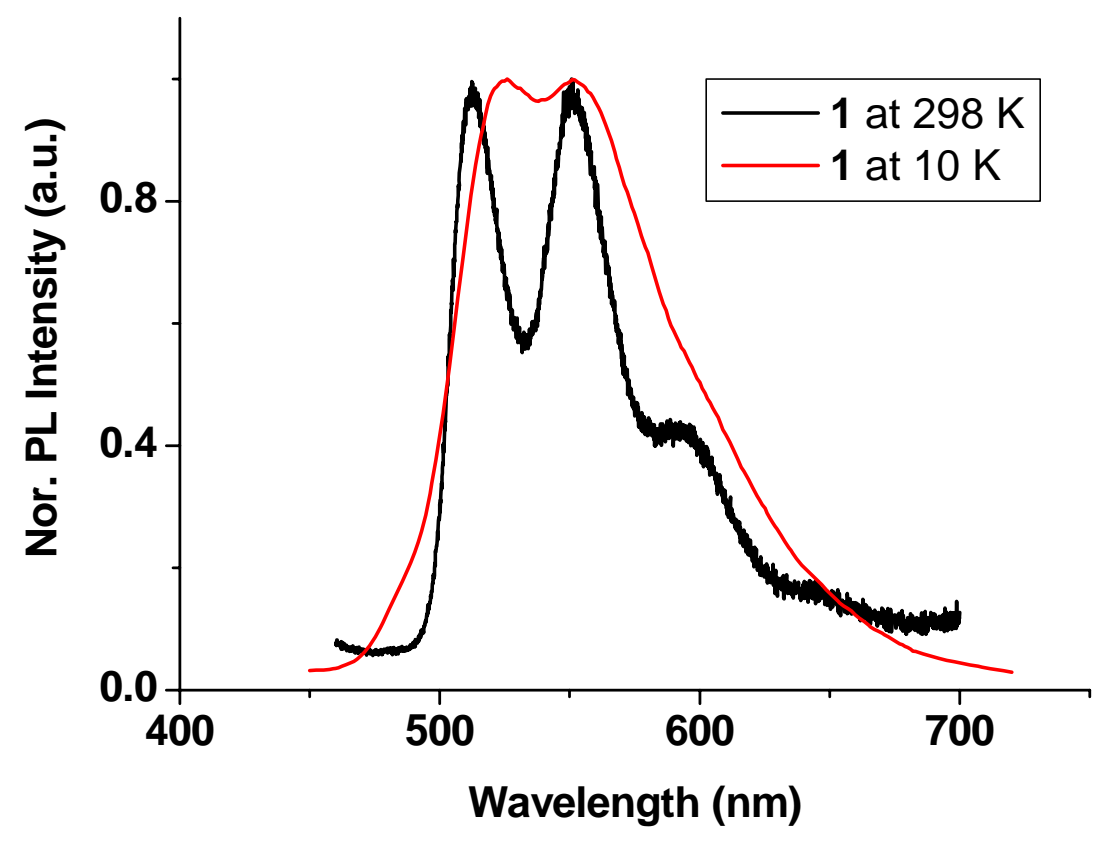

Figure S12. Photoluminescence spectra of 1 in $\mathrm{EtOH} / \mathrm{MeOH}(4: 1, \mathrm{v} / \mathrm{v})$ at room temperature $(298 \mathrm{~K})$ and low temperature $(10 \mathrm{~K})$.

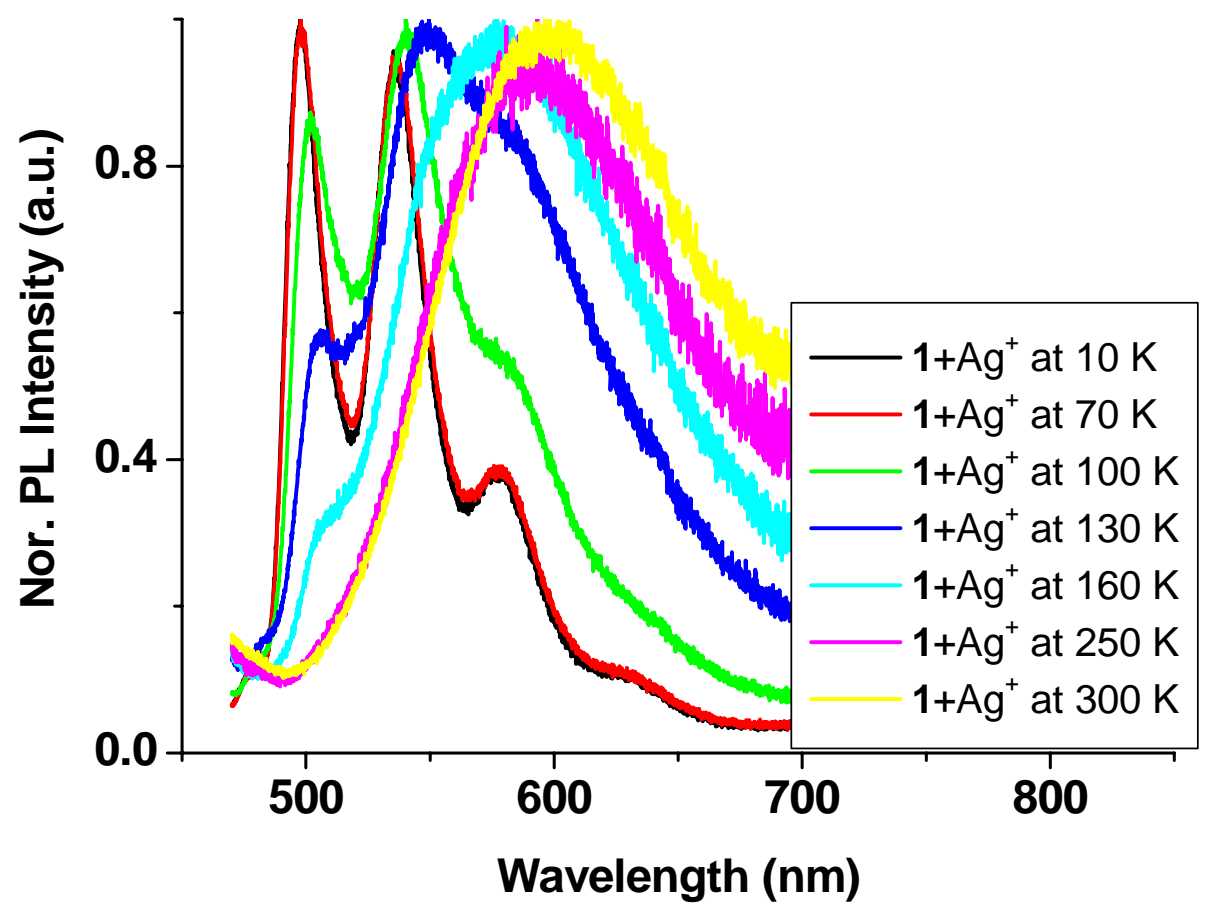

Figure S13. Photoluminescence spectra of $\mathbf{1}$ in EtOH/MeOH $(4: 1, \mathrm{v} / \mathrm{v})$ at different temperatures in the presence of excess amount of $\mathrm{Ag}^{+}$(100 eqs).

Acknowledgements. For the low temperature photoluminescence measurements we are indebted to Prof. Dr. Claudia Wickleder and Hailing Cui (Chemistry Department of the University of Siegen). 